\title{
Delivering mobile eye care to underserved communities while providing training in ophthalmology to medical students: experience of the Guerrilla Eye Service
}

This article was published in the following Dove Medical Press journal: Clinical Ophthalmology

\section{Andrew MWilliams* \\ Benjamin Botsford* \\ Peter Mortensen \\ Daniel Park \\ Evan L Waxman}

Department of Ophthalmology, University of Pittsburgh Medical

Center, Pittsburgh, PA, USA

*These authors contributed equally to this work
Correspondence: Evan L Waxman Department of Ophthalmology, University of Pittsburgh Medical Center, I 400 Locust Street, Suite 3103, Pittsburgh, PA I5219, USA

$\mathrm{Tel}+\mathrm{I} 4126472200$

$\mathrm{Fax}+$ I 4126475119

Email waxmane@upmc.edu
Objective: The objective of the study was to characterize the population served by the student-led Guerrilla Eye Service (GES), a mobile outreach program that delivers comprehensive ophthalmic care to underserved communities in the greater Pittsburgh area.

Patients and methods: Patients attending GES missions at a single urban free clinic from 2012 through 2017 were included in this retrospective case series. All patients underwent a comprehensive eye examination at no cost, with referral to a university eye clinic if necessary. Demographic characteristics, past ocular history, reasons for attendance, and ophthalmic diagnoses were recorded. Attendance rates and treatment outcomes of patients referred to the university eye clinic were also reviewed.

Results: We reviewed records of 360 GES patients (mean age 43 years, age range 1-79 years; 56\% [200] male; 37\% [133] non-English speakers). The most common reasons for attending were blurry vision (28\% [101]), need for new glasses (22\% [80]), and referral for a diabetic eye exam (18\% [63]). The most common diagnosis made was refractive error (59\% [214]), and vouchers for free spectacles were provided. One-third of diabetic patients had retinopathy (32\% [38]). Glaucoma suspect (11\% [40]), narrow angles (4\% [13]), treatment-requiring diabetic eye disease (4\% [14]), and visually-significant cataract (3\% [11]) were diagnoses that most often prompted referral to the university clinic. In all, 114 patients were referred (32\%), of whom $82(72 \%)$ attended the follow-up visit. Other patients continued to receive longitudinal care through GES.

Conclusion: Medical student-led outreach programs under the supervision of an attending ophthalmologist can deliver regular eye care to underserved communities while providing referrals to a university clinic for those with advanced disease.

Keywords: vision health, public health, mobile medical care, eye care, education, community engagement

\section{Introduction}

Many patients in the United States lack access to eye care, resulting in an unnecessary societal burden of preventable and treatable visual impairment. In fact, the 61 million Americans estimated to be at high risk of vision loss are severely underrepresented among patients who receive regular eye exams. ${ }^{1}$ To address the substantial inequity in eye care in the United States, the National Academies of Sciences, Engineering, and Medicine recently called for further action to prioritize vision health in a 2017 report entitled, "Making Eye Health a Population Health Imperative."2 Among other 
recommendations, this report calls for expanding access to clinical care, enhancing public health capabilities in the field of vision, and promoting greater community engagement. ${ }^{3}$

In this manuscript, we describe and analyze our experience with a public health vision outreach initiative that aims to deliver regular vision care to populations in need. The Guerrilla Eye Service (GES), a program established by the Department of Ophthalmology of the University of Pittsburgh School of Medicine, is a medical student-run organization that provides free eye care to underserved patients in the greater Pittsburgh area. Herein, we examine demographic characteristics and comorbidities of patients who have attended GES outreach missions, and identify reasons for attending, ophthalmic diagnoses made, and referral and follow-up rates for further care at our university eye clinic.

\section{Patients and methods}

GES was established in 2006 to fulfill dual goals of delivering eye care to the underserved community and involving medical students with educational opportunities in ophthalmology. GES functions by bringing ophthalmic equipment to primary care clinic sites that focus on caring for the underserved, thereby evaluating patients in settings where they are usually seen for primary care. About $\$ 80,000$ in foundation grants covered initial costs of equipment that could be disassembled and transported by personal vehicle. This equipment includes two phoropters, two laptop computers with Snellen acuity software, a set of trial lenses, a handheld tonometer, an autorefractor, a lensometer, a portable slit lamp, and an indirect ophthalmoscope. A digital fundus camera was purchased and maintained at a single site.

Several trips per month are taken to various sites to provide eye care free of charge to the community, with dates coordinated between the primary care clinics and the medical students of the Ophthalmology Interest Group of the University of Pittsburgh School of Medicine. Each trip taken to provide eye care in the community is described as a service "mission." Missions are staffed by medical students, who obtain a basic history and conduct the initial work up, ophthalmology residents, who aid medical students with refraction, examination, and treatment plans, and a supervising attending ophthalmologist. Medical students of all years participate, predominantly those in their preclinical studies. Involvement of medical students of all years has yielded an institutional memory that keeps the program in continuous operation. One medical student is designated as the team leader for each mission and works to optimize clinic workflow. Patients are scheduled for an appointment through the hosting primary care clinic, with same-day/walk-in appointments also accepted. The clinic sessions are held on evenings and weekends. Professional medical translation services for Spanish are made available on-site for select missions. For other non-English languages, translation is done through accompanying relatives. The general clinic layout is displayed in Figure 1.

A comprehensive eye examination is provided to all patients at no cost. After gathering a general history, medical students measure visual acuity (VA), pupils, and intraocular pressure. Distance and near vision are recorded using a Snellen chart. For pupil examination, pupillary diameter is measured in dark and light, and assessment is made for an afferent pupillary defect. Intraocular pressure is taken with a Tono-Pen (Medtronic, Dublin, Ireland). For patients with a best-corrected VA of 20/30 or worse in at least one eye, medical students obtain autorefraction and lensometry measurements, and ophthalmology residents then assist the students in conducting manifest refraction for spectacle correction. Vouchers are provided from partnering optical shops for free spectacles, and reading glasses are trialed and dispensed on-site at no cost. All patients are screened for presence of narrow angles by Van Herick method at the slit lamp by a resident before dilation. Patients then receive slit lamp biomicroscopy and indirect ophthalmologic examination. Patients with abnormal fundus findings are imaged with the on-site digital retinography system retinal camera (CenterVue, Padova, Italy) to review the findings with the patient and the participating students. Medical students first discuss their patients with a resident to devise a treatment plan. Students then present the history, exam findings, and plan to the attending ophthalmologist, who evaluates each patient and approves final recommendations.

Medical records from each service mission are charted on a standard form by medical students and residents, with final approval by the attending ophthalmologist, and the records are kept at the hosting primary care site to allow the primary care team the longitudinal assess to them. By keeping records of the ophthalmic examination at the primary care site, GES supports the mission of the hosting clinics as patient-centered medical homes.

Patients who are found to have ophthalmic disease that requires treatment, such as initiation of medical therapy, laser treatment, or surgery, are referred for follow-up at our university eye clinic. The names and phone numbers of the referred patients are given to coordinators at the university eye clinic, who call the patients to schedule follow-up. The health system covers the cost of the follow-up clinic 

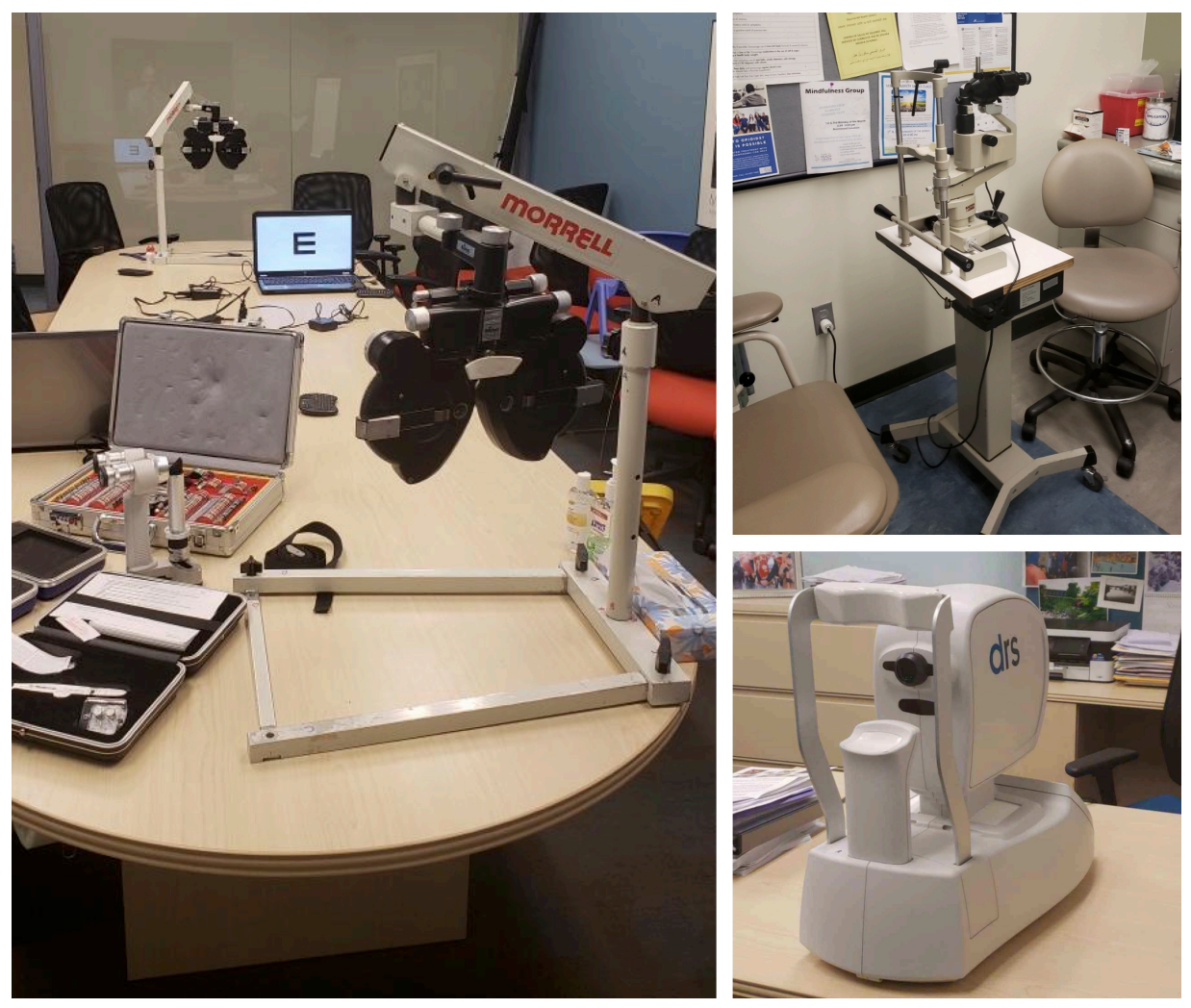

Figure I Equipment on site during a GES mission.

Notes: On the left, two antiparallel lanes are setup on the table for assessing VA with portable phoropters and laptops with Snellen chart software calibrated to available space for the lane. Also depicted are a Tono-Pen, a handheld slit lamp, and a trial lens case. On the right, a portable slit lamp (top) and on-site digital fundus camera (bottom) are setup. Not pictured are the lensometer, autorefractor, or indirect ophthalmoscope. Abbreviations: GES, Guerrilla Eye Service; VA, visual acuity.

encounters and all office-based procedures. Patients are assisted with Medicaid and charity care applications for any necessary operative care.

The frequency of GES missions varies between sites, ranging from monthly to annual visits. One clinic site that is visited on a monthly basis by GES is the Birmingham Free Clinic, which is affiliated with the University of Pittsburgh School of Medicine and provides multispecialty care to the local, underserved community at no cost. Medical records from GES missions are maintained in paper form at the Birmingham Free Clinic, as they are with every clinical site. However, unlike the other locations, the medical records from this university-affiliated clinic are scanned and made available in the electronic medical record of the University of Pittsburgh Medical Center (UPMC). The patient schedule for each date is similarly electronically assessable, as are records of follow-up visits at the university eye clinic. The availability of electronic medical records from the Birmingham Free Clinic makes this site uniquely accessible for retrospective review as a representative site served by GES.
The Institutional Review Board of UPMC deemed this study exempt from full review and waived patient consent due to its retrospective design and anonymous data collection. The dates and sites for all visits conducted by GES since its incorporation of the electronic medical record system in 2012 were recorded. Demographic information was obtained, including age, gender, self-reported race, language spoken, and insurance status. Charts were also reviewed for the reason for attending the eye appointment, past medical history, past ocular history, and whether attendance at more than one GES mission occurred. Additionally, information was collected about the ophthalmic examination, the diagnoses made, whether referral to the UPMC Eye Center was recommended, and, when applicable, whether the recommended referral appointment was attended. All components of this study complied with the Declaration of Helsinki and the Health Insurance Portability and Accountability Act of 1996.

In order to ensure that patients who were seen multiple times by GES were not duplicated, demographic data and reason for attendance from only the first visit was used for analysis. The subsequent visits were reviewed for follow-up 
information, such as eventual referral. We analyzed the earliest visits available as scanned documents in the electronic record, which at times predated the integration of the online scheduling system used to search for patient encounters. For patients with multiple diagnoses who were recommended to follow up at the university eye clinic, only one diagnosis was indicated as a reason for referral in order to avoid duplications in enumerating the number of patients referred. Referral follow up was determined by examining the chart for ophthalmology clinic encounters after referral was made.

For statistical analysis, Snellen VA was converted to the logarithm of the minimum angle of resolution (logMAR) equivalent. Data are summarized using descriptive statistics and reported as mean $\pm \mathrm{SD}$.

\section{Results}

From 2012 to 2017, GES underwent 127 service missions at 14 sites in the greater Pittsburgh area (Table 1). Table 2 summarizes the characteristics of the 360 patients seen at the Birmingham Free Clinic site over 49 missions spanning the 6-year period from 2012 through 2017 . The average age of those who attended was 43 years, with ages ranging from 1 to 79 years, and $200(56 \%)$ of the attendees were male.

Attendees had diverse self-reported racial backgrounds, with 36\% (128) Black, 32\% (116) Hispanic, 19\% (70) White, and the remaining $13 \%$ (46) of other ethnicities. The majority of patients were English speakers (63\% [227]), 29\% (104) spoke only Spanish, and the remaining 8\% (29) spoke one of 17 other languages. None of the 360 attendees reported having health insurance.

A significant number of patients had systemic health conditions, with 33\% (118) reporting a diagnosis of diabetes and $37 \%$ (133) reporting hypertension during intake for their appointment. There was similarly a large burden of selfreported eye conditions, with 46\% (167) reporting a history of visual ailment. The most common ocular condition was refractive error, which was reported by $28 \%$ (100) of patients, followed by history of blunt ocular trauma (4\% [13]) and glaucoma (3\% [12]).

The most common reasons given for attending the eye appointment were blurry vision (28\% [101]), need for new glasses $(22 \%$ [80]), and referral for a diabetic eye exam (18\% [63]). Overall, 14\% (51) of patients attended more than one mission at this site (Table 2).

The best corrected VA ranged widely between clinic attendees. The VA of the better-seeing eye ranged from counting fingers at $3 \mathrm{ft}$ to $20 / 10$, with a mean Snellen acuity of 20/24 ( $\log$ MAR equivalent $0.07 \pm 0.16)$. The range of acuity of the worse-seeing eye spanned from hand motions to $20 / 15$, with a mean Snellen acuity of 20/29 ( $\log$ MAR equivalent $0.16 \pm 0.33$ ). Intraocular pressure measurements averaged $17.1 \pm 3.5 \mathrm{mmHg}$ in the right eye and $17.0 \pm 3.4 \mathrm{mmHg}$ in the left (Table 3).

Manifest refraction led to significant improvement in VA for many patients (Table 4$)$. Over a third of patients $(39 \%$ [138]) presented with VA worse than 20/30, almost all of whom improved by at least one Snellen line with refraction (35\% [122] of right eyes, 34\% [119] of left eyes). Among the 190 patients (53\%) whose VA improved with refraction, there was a mean gain of $0.29 \pm 0.24 \log$ MAR for both right and left eyes, which equates to a gain of 2.9 lines on the Early Treatment of Diabetic Retinopathy Study (ETDRS) chart (Table 4).

Attendees from GES were found to have a range of ophthalmic diagnoses. As detailed in Table 5, the most common diagnosis was refractive error (59\% [214]). The second most common diagnosis related to diabetes, as

Table I List of the I4 sites visited over 127 service missions by GES, 2012-2017

\begin{tabular}{|l|l|l|}
\hline Clinics & Location & Number of visits \\
\hline Birmingham Free Clinic & Pittsburgh, PA & 49 \\
Squirrel Hill Health Center & Pittsburgh, PA & 28 \\
Cornerstone Care Community Health Center & Greensboro, PA & 8 \\
Cornerstone Care Community Health Center & Waynesburg, PA & 8 \\
East End Community Health Center & Pittsburgh, PA & 8 \\
Ninth Street Free Clinic & McKeesport, PA & 7 \\
Organization for Chinese Americans Health Clinic & Pittsburgh, PA & 4 \\
Steubenville Veterans' Affairs Outpatient Clinic & Steubenville, OH & 4 \\
Verland Residential Treatment Center & Sewickley, PA & 4 \\
East Liberty Family Health Care Center & Pittsburgh, PA & 2 \\
Majesty Care Free Clinic & Greensburg, PA & 2 \\
Butler Center for Community Resources & Butler, PA & 1 \\
Catholic Charities Free Healthcare Center & Pittsburgh, PA & I \\
Hazelwood Family Health Center & Pittsburgh, PA & 1 \\
\hline
\end{tabular}

Note: aPatient data from the Birmingham Free Clinic site were available for inclusion in the present study.

Abbreviation: GES, Guerrilla Eye Service. 
Table 2 Characteristics of 360 patients seen by GES at the Birmingham Free Clinic site, 2012-2017

\begin{tabular}{|c|c|}
\hline Characteristics & Mean \pm SD (range) \\
\hline \multirow[t]{2}{*}{ Age, years } & $43 \pm 18(1-79)$ \\
\hline & $n(\%)(N=360)$ \\
\hline \multicolumn{2}{|l|}{ Gender } \\
\hline Male & $200(56)$ \\
\hline Female & $160(44)$ \\
\hline \multicolumn{2}{|l|}{ Race/ethnicity } \\
\hline Black & $128(36)$ \\
\hline Hispanic & $116(32)$ \\
\hline White & $70(19)$ \\
\hline Asian or Southeast Asian & $30(8)$ \\
\hline Middle Eastern & $10(3)$ \\
\hline Native American & $\mathrm{I}(0.3)$ \\
\hline Inuit & I $(0.3)$ \\
\hline Unknown & $4(I)$ \\
\hline \multicolumn{2}{|l|}{ Language spoken } \\
\hline English & $227(63)$ \\
\hline Spanish & $104(29)$ \\
\hline Arabic & $5(1)$ \\
\hline Mandarin & $4(1)$ \\
\hline Amharic & $2(0.6)$ \\
\hline Bengali & $2(0.6)$ \\
\hline French & $2(0.6)$ \\
\hline Nepali & $2(0.6)$ \\
\hline Tagalog & $2(0.6)$ \\
\hline Burmese (Karen) & $\mathrm{I}(0.3)$ \\
\hline Ganda & $\mathrm{I}(0.3)$ \\
\hline Gujrati & $\mathrm{I}(0.3)$ \\
\hline Hindi & $\mathrm{I}(0.3)$ \\
\hline Persian & $\mathrm{I}(0.3)$ \\
\hline Portuguese & $\mathrm{I}(0.3)$ \\
\hline Russian & $\mathrm{I}(0.3)$ \\
\hline Swahili & $\mathrm{I}(0.3)$ \\
\hline Turkish & $\mathrm{I}(0.3)$ \\
\hline Vietnamese & $\mathrm{I}(0.3)$ \\
\hline \multicolumn{2}{|l|}{ Health insurance status } \\
\hline No insurance & $360(100)$ \\
\hline \multicolumn{2}{|l|}{ Medical history } \\
\hline Diabetes mellitus & $118(33)$ \\
\hline Hypertension & $133(37)$ \\
\hline \multicolumn{2}{|l|}{ Past ocular history ${ }^{\mathrm{a}}$} \\
\hline Refractive error & $100(28)$ \\
\hline Myopia & $38(\mathrm{II})$ \\
\hline Hyperopia & $10(3)$ \\
\hline Presbyopia & $24(7)$ \\
\hline Unspecified & $28(8)$ \\
\hline Trauma, blunt & $13(4)$ \\
\hline Glaucoma & $12(3)$ \\
\hline Amblyopia or strabismus & $9(3)$ \\
\hline Cataracts & $8(2)$ \\
\hline Dry eye syndrome & $5(1)$ \\
\hline Ocular foreign body & $5(1)$ \\
\hline Keratitis & $5(1)$ \\
\hline Perforated corneal ulcer & $\mathrm{I}(0.3)$ \\
\hline Anterior laser treatment & $4(I)$ \\
\hline LPI & $\mathrm{I}(0.3)$ \\
\hline LASIK & $\mathrm{I}(0.3)$ \\
\hline Radial keratotomy & $\mathrm{I}(0.3)$ \\
\hline
\end{tabular}

(Continued)
Table 2 (Continued)

\begin{tabular}{|c|c|}
\hline Characteristics & n (\%) $(\mathrm{N}=360)$ \\
\hline Unspecified refractive procedure & $\mathrm{I}(0.3)$ \\
\hline Diabetic retinopathy & $4(1)$ \\
\hline Prior laser or injection & $3(1)$ \\
\hline Allergic conjunctivitis & $4(I)$ \\
\hline Cataract surgery & $3(1)$ \\
\hline Contact lens use & $2(I)$ \\
\hline Chalazion or stye & $2(I)$ \\
\hline Pterygium & $2(1)$ \\
\hline Retinal tear or detachment & $2(1)$ \\
\hline BRVO & $\mathrm{I}(0.3)$ \\
\hline Chemical exposure & $\mathrm{I}(0.3)$ \\
\hline Choroidal nevus & $\mathrm{I}(0.3)$ \\
\hline Corneal abrasion & $\mathrm{I}(0.3)$ \\
\hline Retinitis pigmentosa & $\mathrm{I}(0.3)$ \\
\hline Scleritis & $\mathrm{I}(0.3)$ \\
\hline None & $193(54)$ \\
\hline \multicolumn{2}{|l|}{ Reason for attending ${ }^{\mathrm{a}}$} \\
\hline Blurry vision & $101(28)$ \\
\hline New glasses & $80(22)$ \\
\hline Lost/broken glasses & $5(1)$ \\
\hline Diabetic eye exam & $63(18)$ \\
\hline Routine exam & $24(7)$ \\
\hline For driver license & $2(1)$ \\
\hline For work & $\mathrm{I}(0.3)$ \\
\hline Dry or itchy eyes & $20(6)$ \\
\hline Eye burning & $13(4)$ \\
\hline Decreased vision & II (3) \\
\hline Failed vision screen & $10(3)$ \\
\hline Flashes or floaters & $9(3)$ \\
\hline Eye redness & $8(2)$ \\
\hline Cataracts & $7(2)$ \\
\hline Glaucoma check up & $6(2)$ \\
\hline Tearing & $6(2)$ \\
\hline Eye pain or strain & $5(1)$ \\
\hline Headache & $4(I)$ \\
\hline Stye & $4(1)$ \\
\hline Strabismus & $3(1)$ \\
\hline Allergic conjunctivitis & $2(1)$ \\
\hline Diplopia & $2(1)$ \\
\hline Family history of glaucoma & $2(1)$ \\
\hline Glare or haloes & $2(I)$ \\
\hline Trauma & $2(1)$ \\
\hline Unilateral vision loss & $2(1)$ \\
\hline Foreign body sensation & $\mathrm{I}(0.3)$ \\
\hline Metamorphopsia & $\mathrm{I}(0.3)$ \\
\hline Nevus check up & $\mathrm{I}(0.3)$ \\
\hline Photophobia & $\mathrm{I}(0.3)$ \\
\hline Pterygium & $\mathrm{I}(0.3)$ \\
\hline Toxicity screen (tuberculosis medications) & $\mathrm{I}(0.3)$ \\
\hline Attended multiple GES missions & $51(14)$ \\
\hline
\end{tabular}

Note: aSome subjects had multiple past ocular conditions or reasons for attending. Abbreviations: BRVO, branch retinal vein occlusion; GES, Guerrilla Eye Service; LASIK, laser assisted in situ keratomileusis; LPI, laser peripheral iridotomy.

$33 \%$ (118) of all attendees had a self-reported history of diabetes mellitus. Of these, a third (38) - or $11 \%$ of the total population seen - had some degree of diabetic eye disease. Mild non-proliferative diabetic retinopathy (NPDR) was 
Table 3 Best corrected VA and intraocular pressure measurements for patients seen by GES at the Birmingham Free Clinic site, 2012-2017

\begin{tabular}{|c|c|c|c|c|}
\hline & \multicolumn{2}{|c|}{ Best corrected VA (logMAR, Snellen equivalent) } & \multicolumn{2}{|c|}{ Intraocular pressure $(\mathrm{mmHg})$} \\
\hline & Better-seeing eye & Worse-seeing eye & Right eye & Left eye \\
\hline $\begin{array}{l}\text { Mean } \pm S D \\
\text { Range } \\
n\end{array}$ & $\begin{array}{l}0.07(20 / 24) \pm 0.16 \\
2(\mathrm{CF} \text { at } 3 \mathrm{ft}) \text { to }-0.3(20 / 10) \\
354\end{array}$ & $\begin{array}{l}0.16(20 / 29) \pm 0.33 \\
3(\mathrm{HM} \text { only) to }-0.12(20 / 15) \\
354\end{array}$ & $\begin{array}{l}17.1 \pm 3.5 \\
8-34 \\
333\end{array}$ & $\begin{array}{l}17.0 \pm 3.4 \\
10-35 \\
333\end{array}$ \\
\hline
\end{tabular}

Notes: For VA, three patients had missing data, two different patients had no light perception and thus unable to be converted to logMAR and included in the analysis, and one was measured as central, steady, and maintained. For intraocular pressure, measurement was either refused by or data missing for 27 cases. Intraocular pressure was measured by Tono-Pen.

Abbreviations: CF, counting fingers; GES, Guerrilla Eye Service; HM, hand motions; logMAR, logarithm of the minimum angle of resolution; VA, visual acuity.

seen in $5 \%(18)$, moderate in $2 \%(6)$, and severe in $1 \%(5)$ of the total population. All five patients who were found to have severe NPDR were referred to the university eye clinic, three of whom followed up and underwent panretinal photocoagulation (PRP). Similarly, six patients were found to have proliferative diabetic retinopathy, and all were referred, followed up, and underwent treatment (four with PRP, one with anti-vascular endothelial growth factor (VEGF) injections, and one with vitrectomy due to presence of tractional retinal detachments). Finally, three patients were found to have diabetic macular edema, and all three followed up and underwent focal laser (two patients) or anti-VEGF injections (one patient).

GES also diagnosed and arranged surgery for several patients with visual impairment from cataracts. Three percent, or eleven patients, were found to have a visually-significant cataract, meaning VA was reduced to at least 20/40 and symptoms interfered with daily life. All eleven were referred for cataract surgery, eight followed up, and seven underwent phacoemulsification with intraocular lens implantation over this study period.

A diagnosis of glaucoma or glaucoma suspect was another common reason for referral to the university clinic, which affected $11 \%$ (40) of all patients seen. The diagnosis of glaucoma suspect was made based on cup to disc ratio, cup to disc asymmetry, or elevated intraocular pressure. In all, 31 glaucoma suspects were referred for a university clinic visit, of whom 22 (71\%) attended. Those with a formal diagnosis of glaucoma maintained care through the university clinic. Additionally, 13 patients (4\%) were noted to have narrow

Table $4 \mathrm{VA}$ and uncorrected refractive error

\begin{tabular}{|c|c|c|}
\hline & Right eye & Left eye \\
\hline \multicolumn{3}{|l|}{ VA at presentation, $\mathrm{n}(\%)$} \\
\hline Normal ( $20 / 30$ or better) & $213(6 I)$ & $2 \mid 4(6 I)$ \\
\hline Reduced, improvement with refraction & $122(35)$ & $119(34)$ \\
\hline Correctable to $20 / 30$ or better & $92(26)$ & $85(24)$ \\
\hline Impaired, no improvement with refraction & $16(5)$ & $18(5)$ \\
\hline \multicolumn{3}{|l|}{ Improvement in VA with refraction } \\
\hline \multicolumn{3}{|l|}{ Presenting VA, all patients } \\
\hline LogMAR, mean $\pm S D, n$ & $0.28 \pm 0.36,35$ I & $0.30 \pm 0.43,350$ \\
\hline Snellen equivalent, mean & $20 / 38$ & $20 / 40$ \\
\hline \multicolumn{3}{|l|}{ Best-corrected VA, all patients } \\
\hline LogMAR, mean $\pm S D, n$ & $0.12 \pm 0.27,35 \mid$ & $0.14 \pm 0.34,350$ \\
\hline Snellen equivalent, mean & $20 / 26$ & $20 / 28$ \\
\hline \multicolumn{3}{|l|}{ Improvement in VA, all patients } \\
\hline LogMAR, mean $\pm S D, n$ & $0.15 \pm 0.23,351$ & $0.16 \pm 0.23,350$ \\
\hline Lines gained, ${ }^{\mathrm{a}}$ mean & 1.5 & 1.6 \\
\hline \multicolumn{3}{|l|}{ Improvement in VA, patients with refraction ${ }^{\mathrm{b}}$} \\
\hline LogMAR, mean $\pm S D, n$ & $0.29 \pm 0.24,187$ & $0.29 \pm 0.24,190$ \\
\hline Lines gained, ${ }^{\mathrm{a}}$ mean & 2.9 & 2.9 \\
\hline
\end{tabular}

Notes: Distance VA was used for analysis. VA measurements were taken using a Snellen chart. Acuity was assessed with correction for patients who presented with spectacles. Nine patients had missing data or VA that could not be converted to logMAR (hand motions or worse; fix-and-follow). An additional patient had hand motions or worse VA in the left eye than the right. VA was considered improved with refraction if at least one Snellen line was gained on manifest refraction. alines of vision gained on the ETDRS chart, by which an improvement of 0.1 logMAR equals a gain of one line. 'lncludes all patients whose vision improved with refraction by any amount regardless of presenting VA.

Abbreviations: ETDRS, Early Treatment of Diabetic Retinopathy Study; VA, visual acuity; logMAR, logarithm of the minimum angle of resolution. 
angles by Van Herick method and/or gonioscopy, 12 of whom were referred to the university eye clinic, and seven of these attended the referral appointment (58\%). All seven of those who attended follow-up underwent prophylactic laser peripheral iridotomy (LPI).

In several instances, presentation for an eye-related complaint led to a diagnosis of potentially life-threatening disease. One patient presented with diplopia that localized to a fourth cranial nerve palsy. Referral for advanced imaging led to a diagnosis of pontine schwannoma and referral to neurosurgery. Another patient with blurry vision was found to have bilateral disc edema, prompting referral to the emergency department for urgent imaging and work up. She was ultimately diagnosed with pseudotumor cerebri and maintained follow-up with the university eye clinic. Finally, a patient presented with amaurosis fugax and signs of ocular ischemic syndrome, with further testing revealing for severe carotid stenosis that was eventually treated with carotid endarterectomy (Table 5).

In total, 62 eye-related diagnoses were made. Of the 114 (32\%) patients referred to the university eye clinic, 82 of them (72\%) presented for the recommend follow-up visit (Table 5).

Table 5 Diagnoses and referrals made for 360 patients seen by GES at the Birmingham Free Clinic site, 2012-2017

\begin{tabular}{|c|c|c|c|c|}
\hline Diagnosis $^{a}$ & $\begin{array}{l}\text { Patients, } \\
\text { n (\%) }\end{array}$ & $\begin{array}{l}\text { Referred to } \\
\text { UPMC Eye } \\
\text { Center, } n\end{array}$ & $\begin{array}{l}\text { Attended } \\
\text { referral } \\
\text { appt., } n\end{array}$ & Comments \\
\hline Refractive error & $214(59)$ & & & \\
\hline Hyperopia & $26(7)$ & & & \\
\hline Myopia & $95(26)$ & I & I & \\
\hline Presbyopia & $51(14)$ & & & \\
\hline Unspecified & $42(12)$ & 4 & 2 & $\begin{array}{l}\text { Four were referred to the pediatric service for cycloplegic } \\
\text { refraction }\end{array}$ \\
\hline Diabetes mellitus & $118(33)$ & & & \\
\hline No retinopathy & $80(22)$ & & & \\
\hline Mild NPDR & $18(5)$ & 3 & I & \\
\hline Moderate NPDR & $6(2)$ & 4 & 2 & One patient died before follow-up \\
\hline Severe NPDR & $5(1)$ & 5 & 3 & All three referred underwent PRP \\
\hline PDR & $6(2)$ & 6 & 6 & $\begin{array}{l}\text { Four had PRP, one had bilateral anti-VEGF injections with plan } \\
\text { for PPV, and one had PPV due to presence of tractional retinal } \\
\text { detachments }\end{array}$ \\
\hline $\begin{array}{l}\text { Diabetic macular edema } \\
\text { (center-involving) }\end{array}$ & $3(1)$ & 3 & 3 & $\begin{array}{l}\text { Two received focal laser treatment and one received anti-VEGF } \\
\text { injections }\end{array}$ \\
\hline Cataract & $60(17)$ & & & \\
\hline Not visually significant & $49(14)$ & & & \\
\hline Visually significant & II (3) & 11 & 8 & $\begin{array}{l}\text { Seven had cataract surgery, and one attended preoperative } \\
\text { visit only }\end{array}$ \\
\hline Dry eye syndrome or blepharitis & $54(15)$ & 3 & 2 & \\
\hline Glaucoma or glaucoma suspect & $40(\mathrm{II})$ & 31 & 22 & $\begin{array}{l}\text { One with chronic angle closure glaucoma, and one with } \\
\text { neovascular glaucoma }\end{array}$ \\
\hline Pinguecula or pterygium & $16(4)$ & & & \\
\hline Hypertensive retinopathy & $14(4)$ & 2 & I & \\
\hline Narrow angles & $13(4)$ & 12 & 7 & All of those attending the referral appointment underwent LPI \\
\hline Allergic conjunctivitis & $12(3)$ & 1 & I & \\
\hline Amblyopia & $8(2)$ & & & \\
\hline Strabismus & $7(2)$ & 4 & 4 & \\
\hline Posterior vitreous detachment & $4(1)$ & & & \\
\hline Chalazion or stye & $3(1)$ & & & \\
\hline Lattice degeneration & $3(1)$ & & & \\
\hline Macular RPE mottling & $3(1)$ & I & I & \\
\hline Age-related macular degeneration & $2(1)$ & 1 & I & \\
\hline Choroidal nevus & $2(1)$ & & & \\
\hline Dellen & $2(1)$ & & & \\
\hline Eyelid papilloma & $2(1)$ & 2 & I & \\
\hline Macular drusen & $2(1)$ & & & \\
\hline Migraine & $4(I)$ & & & \\
\hline
\end{tabular}


Table 5 (Continued)

\begin{tabular}{|c|c|c|c|c|}
\hline Diagnosis $^{a}$ & $\begin{array}{l}\text { Patients, } \\
\text { n (\%) }\end{array}$ & $\begin{array}{l}\text { Referred to } \\
\text { UPMC Eye } \\
\text { Center, } \mathbf{n}\end{array}$ & $\begin{array}{l}\text { Attended } \\
\text { referral } \\
\text { appt., } n\end{array}$ & Comments \\
\hline Posterior capsular opacity & $3(1)$ & & & \\
\hline Not visually significant & $2(I)$ & & & \\
\hline Visually significant & $\mathrm{I}(0.3)$ & I & I & Underwent YAG capsulotomy \\
\hline Thyroid eye disease & $2(1)$ & I & I & $\begin{array}{l}\text { Referred to internal medicine for management of thyroid } \\
\text { disease }\end{array}$ \\
\hline Amaurosis fugax & I $(0.3)$ & I & I & $\begin{array}{l}\text { Found to have carotid stenosis and ocular ischemic syndrome, } \\
\text { referred to vascular surgery }\end{array}$ \\
\hline Anterior uveitis & $\mathrm{I}(0.3)$ & I & I & \\
\hline Asteroid hyalosis & $\mathrm{I}(0.3)$ & & & \\
\hline BRVO & I (0.3) & I & I & \\
\hline Conjunctival nevus & I $(0.3)$ & I & I & Nevus was excised \\
\hline Constricted visual fields & I $(0.3)$ & I & 0 & \\
\hline Corneal abrasion & I $(0.3)$ & & & \\
\hline Corneal foreign body & $\mathrm{I}(0.3)$ & I & I & \\
\hline Corneal scar & $2(1)$ & & & \\
\hline Cranial nerve 4 palsy & $\mathrm{I}(0.3)$ & I & I & Found to have pontine schwannoma, referred to neurosurgery \\
\hline ERM & I $(0.3)$ & & & \\
\hline Esotropia & I $(0.3)$ & & & \\
\hline Fuchs' dystrophy & $\mathrm{I}(0.3)$ & & & \\
\hline Full-thickness macular hole & $\mathrm{I}(0.3)$ & I & I & $\begin{array}{l}\text { The patient underwent PPV and gas bubble repair of } \\
\text { macular hole }\end{array}$ \\
\hline Iridodialysis & $\mathrm{I}(0.3)$ & & & \\
\hline Keratoconus & I $(0.3)$ & I & 0 & \\
\hline Macular scar & I $(0.3)$ & & & \\
\hline Maculopathy & $\mathrm{I}(0.3)$ & I & I & \\
\hline Optic disc drusen & $\mathrm{I}(0.3)$ & & & \\
\hline Optic disc edema & I (0.3) & I & I & $\begin{array}{l}\text { Sent to the emergency department and ultimately diagnosed } \\
\text { with pseudotumor cerebri; started treatment and followed } \\
\text { in clinic }\end{array}$ \\
\hline Phthisis bulbi & $\mathrm{I}(0.3)$ & I & I & \\
\hline Post-traumatic glaucoma & $\mathrm{I}(0.3)$ & I & I & \\
\hline Ptosis of upper lids & $\mathrm{I}(0.3)$ & I & 0 & \\
\hline Retinal scarring & $\mathrm{I}(0.3)$ & I & 0 & \\
\hline Retinitis pigmentosa & I $(0.3)$ & I & I & \\
\hline Traumatic mydriasis & I $(0.3)$ & I & I & \\
\hline Traumatic optic neuropathy & $\mathrm{I}(0.3)$ & & & \\
\hline Unexplained vision loss & I $(0.3)$ & I & I & Work up most consistent with nutritional optic neuropathy \\
\hline Viral conjunctivitis & $\mathrm{I}(0.3)$ & & & \\
\hline
\end{tabular}

Note: aSome subjects had multiple diagnoses, and others had none.

Abbreviations: Appt., appointment; BRVO, branch retinal vein occlusion; ERM, epiretinal membrane; LPI, laser peripheral iridotomy; n, number; NPDR, non-proliferative diabetic retinopathy; PDR, proliferative diabetic retinopathy; PPV, pars plana vitrectomy; PRP, panretinal photocoagulation; UPMC, University of Pittsburgh Medical Center; VEGF, vascular endothelial growth factor; RPE, retinal pigment epithelium; YAG, yttrium aluminum garnet.

\section{Discussion}

GES was established to provide much-needed eye care to the underserved communities in the greater Pittsburgh area. By collaborating with local primary care clinics that serve communities in need, this program brings comprehensive eye care to low-income areas that generally lack access to specialists. Instead of providing screening or triage, providers with GES serve the community as the comprehensive eye doctors for the patients at the hosting site. At a single site served by GES, 360 uninsured patients received comprehensive eye exams over a 6-year period. Of these,
214 patients $(59 \%)$ received reading glasses on site and/or a prescription for distance spectacles with a voucher to redeem free glasses at partnering optical shops. Of the 190 (53\%) who were prescribed distance glasses, manifest refraction improved VA by a mean of 2.9 ETDRS lines, highlighting the impact of addressing uncorrected refractive error in the community. ${ }^{4}$ Additionally, 118 patients received diabetic eye exams, a third of whom had some degree of diabetic eye disease. Diabetic patients without retinopathy and those with mild NPDR continue to receive regular screening during service missions to their primary care site, while those in 
need of advanced eye care are referred to the university clinic for treatment and subspecialty care at no cost. Additionally, glaucoma suspect (11\% [40]), narrow angles (4\% [13]), visually-significant cataract (3\% [11]) were diagnosed and prompted referral and treatment. Overall, $72 \%$ of patients who were referred $(82 / 114)$ attended the recommended follow up visit and received treatments including intravitreal injections, pars plana vitrectomy, retinal laser treatment, LPI, and cataract surgery. Notably, in a few cases, ophthalmic evaluation led to detection of serious conditions, including pontine schwannoma, pseudotumor cerebri, and ocular ischemic syndrome/carotid insufficiency. In all, these findings highlight the need for comprehensive eye care in the community that this medical student-led program aims to address.

Other community vision outreach programs have been described, ${ }^{5,6}$ some with an emphasis on medical student involvement. Byrd et $\mathrm{al}^{7}$ described the University of New Mexico Community Vision Project, which delivers mobile care to rural communities with integration of medical student volunteers. A similar eye screening program with medical student involvement has been initiated at Dartmouth College, in which medical students screened 103 patients with a basic eye exam, of whom 74 were found to have abnormal findings that prompted referral to an eye clinic. ${ }^{8}$ Similarly, a pilot initiative at Georgetown University has been described, with the aim to deliver eye screening at a local homeless shelter, and a student-led program at the University of Minnesota resulted in eye examinations for 50 patients, who averaged an $89 \%$ satisfaction rate. ${ }^{10}$

Like GES, at least one other student-led program aims to deliver regular, comprehensive eye care to community sites. At the University of Rochester, medical students lead an ophthalmology service effort through the UR Well Eye Care program. ${ }^{11}$ This program evaluated 148 patients between 2008 and 2013 among an uninsured, urban community. The most common diagnoses given to patients at Rochester were refractive error $(26 \%)$, cataract $(20 \%)$, glaucoma suspect $(10 \%)$, dry eye $(8 \%)$, and diabetic retinopathy $(8 \%)$, which are overall similar to the rates from GES. While 54\% were able to continue their longitudinal eye care through the Rochester program, 16\% were referred to the university eye clinic for advanced care (for comparison, 32\% were referred from our program). It is not known how many patients from the Rochester program attended the recommended follow up appointment. GES and the UR Well programs demonstrate models for medical student-led initiatives to deliver longitudinal and comprehensive eye care to the underserved under the supervision of an attending ophthalmologist. These immersion experiences align well with the best practices in teaching ophthalmology to medical students. ${ }^{12-14}$

While GES program has many strengths, including delivery of care at community sites and a high rate of referral follow up, it does also have shortcomings. The program visits individual sites only periodically, limiting availability for urgent visits. Additionally, while glasses vouchers are given, distance spectacles are not fitted or dispensed on site, and it is unknown how many patients fill their glasses vouchers.

\section{Limitations}

Our study also has several limitations. Incomplete documentation was encountered during this retrospective case-series study, which could affect the accuracy of the summarized data. The reliance on self-reported medical and ocular history may also result in an underestimation of asymptomatic or unrecognized conditions, such as hypertension. Similarly, the level of detail in documentation varied from patient to patient. For example, it is likely that more patients had common ailments like presbyopia, non-visually significant cataract, and posterior vitreous detachment than reported in this study due to absence of documentation. Additionally, it is feasible that some patients who were recommended university follow up sought care with an ophthalmologist outside of our system. Importantly, only a single clinic location was used to examine a population of patients seen by GES due to greater availability of documentation. It is unknown if patients seen at the other 14 community sites share the characteristics of the population described herein from the Birmingham Free Clinic site. In particular, patients from more distant community centers may have lower rates of follow up after referral to our university eye clinic, as greater geographic distance is a known barrier to follow-up adherence. $^{15}$

It is also unknown how patients feel about their experience in this program, and future research could involve surveys or interviews with patients about their experience with GES. Along the same lines, this study lacks data on the experience of the medical students involved, and it is unknown whether this program directly improves ophthalmic knowledge, positively influences students toward a career in ophthalmology, or inspires more community service activity among students who participate. Future research on the experiences of both patients and medical students is warranted.

\section{Conclusion}

Our study suggests that programs led by medical students and supervised by an attending ophthalmologist can deliver 
regular, comprehensive eye care to underserved communities. Referral to a university eye clinic for advanced care was generally successful. Partnerships with participating primary care clinics and funding organizations are critical to continue engagement and to maximize community impact. Future research will be required to assess patient and medical student feedback on such programs. Initiatives like these may help to deliver on national demands to make vision health a priority. ${ }^{2}$

\section{Acknowledgments}

The authors are grateful for all of the medical students, residents, attending ophthalmologists, coordinators, staff, and patients who make the program possible. They are also thankful to the Eye and Ear Foundation, Pittsburgh, PA for their assistance.

\section{Disclosure}

The authors report no conflicts of interest in this work.

\section{References}

1. Zhang X, Saaddine JB, Lee PP, et al. Eye care in the United States: do we deliver to high-risk people who can benefit most from it? Arch Ophthalmol. 2007;125(3):411-418.

2. Welp A, Woodbury RB, McCoy MA, Teutsch SM, editors. Making eye health a population health imperative: vision for tomorrow. Washington, DC: national Academies Press (US); 2016.

3. Lee PP. Vision and public health: framing a purpose for our work. Ophthalmology. 2017;124(2):148-150.
4. Vitale S, Cotch MF, Sperduto RD. Prevalence of visual impairment in the United States. JAMA. 2006;295(18):2158-2163.

5. Dotan G, Truong B, Snitzer M, et al. Outcomes of an inner-city vision outreach program: give kids sight day. JAMA Ophthalmol. 2015;133(5): 527-532.

6. Griffith JF, Wilson R, Cimino HC, Patthoff M, Martin DF, Traboulsi EI. The use of a mobile van for school vision screening: results of 63841 evaluations. Am J Ophthalmol. 2016;163:108-114.

7. Byrd JM, Longmire MR, Syme NP, Murray-Krezan C, Rose L. A pilot study on providing ophthalmic training to medical students while initiating a sustainable eye care effort for the underserved. JAMA Ophthalmol. 2014;132(3):304-309.

8. Tsui E, Siedlecki AN, Deng J, et al. Implementation of a visionscreening program in rural northeastern United States. Clin Ophthalmol. 2015;9:1883-1887.

9. Linson E, Zanganeh T, Korchak M, Lustbader J. Georgetown eye health Initiative. J Student-Run Clinics. 2016;2(1).

10. Downie E, von Hohenberg M, Harrison AA, Sick B. Student-run free clinic as a source of meaningful ophthalmologic care for underserved patients. J Student-Run Clinics. 2017;3(1).

11. Maclean K, Hindman HB. UR well eye care: a model for medical student ophthalmology education and service in the community. Clin Ophthalmol. 2014;8:2397-2401.

12. Succar T, Grigg J, Beaver HA, Lee AG. A systematic review of best practices in teaching ophthalmology to medical students. Surv Ophthalmol. 2016;61(1):83-94.

13. Shah M, Knoch D, Waxman E. The state of ophthalmology medical student education in the United States and Canada, 2012 through 2013. Ophthalmology. 2014;121(6):1160-1163.

14. Graubart EB, Waxman EL, Forster SH, et al. Ophthalmology objectives for medical students: revisiting what every graduating medical student should know. Ophthalmology. 2018;125(12):1842-1843.

15. Zhao D, Guallar E, Bowie JV, et al. Improving follow-up and reducing barriers for eye screenings in communities: the stop glaucoma study. Am J Ophthalmol. 2018;188:19-28.
Clinical Ophthalmology

\section{Publish your work in this journal}

Clinical Ophthalmology is an international, peer-reviewed journal covering all subspecialties within ophthalmology. Key topics include: Optometry; Visual science; Pharmacology and drug therapy in eye diseases; Basic Sciences; Primary and Secondary eye care; Patient Safety and Quality of Care Improvements. This journal is indexed on Submit your manuscript here: http://www.dovepress.com/clinical-ophthalmology-journal

\section{Dovepress}

PubMed Central and CAS, and is the official journal of The Society of Clinical Ophthalmology (SCO). The manuscript management system is completely online and includes a very quick and fair peer-review system, which is all easy to use. Visit http://www.dovepress.com/ testimonials.php to read real quotes from published authors. 